\title{
Global Distribution of Marginal Accessory Cusps of the Maxillary Premolars
}

\author{
Donovan M. Adams ${ }^{1 *}$, Victoria M. Swenson ${ }^{1}$, and G. Richard Scott ${ }^{1}$ \\ ${ }^{1}$ Department of Anthropology, University of Nevada, Reno, NV USA
}

Keywords: marginal accessory cusps, maxillary premolars, ASUDAS, dental morphology

\begin{abstract}
The present study assesses the global distribution of marginal accessory cusps of the maxillary premolars. This trait, despite constituting one of the variables standardized by Turner and colleagues (1991), has received little attention in morphological studies. Frequencies were calculated from data sheets collected by Christy G. Turner II for mesial, distal, and mesial + distal grades. Different geographic patterns were identified for both types of expression on the upper premolars. The patterned geographic distribution of these traits indicates their utility in biodistance investigations. In addition, the distinction between mesial and distal accessory cusps specified by Scott and Irish (2017) is recommended, as these two traits exhibit different geographic patterns.
\end{abstract}

Despite marginal accessory cusps of the maxillary premolars comprising part of the Arizona State University Dental Anthropology System (ASUDAS; Turner et al., 1991), few data are available on their geographic distribution (Hanihara, 2008; Reyes-Centeno et al., 2017; Scott and Irish, 2017). This trait is characterized by additional cusps on either the mesial, distal, or both margins of the maxillary premolar apart from the primary buccal and lingual cusps. These are distinguished from the primary cusps by discrete parallel grooves (Figures 1 and 2). To be scored as a premolar accessory cusp, there has to be separating grooves (Turner et al., 1991). According to the ASUDAS, this trait is scored as present or absent (Turner et al., 1991). However, recent revisions to the ASUDAS published by Scott and Irish (2017) have amended scoring to specify where these cusps are located:

Grade 0: Marginal accessory cusp is absent. Grade 1: Marginal accessory cusp is mesial. Grade 2: Marginal accessory cusp is distal. Grade 3: Marginal accessory cusps are present on the mesial and distal margin.

Marginal accessory cusps have been identified in ancient hominins. This trait has frequently been noted in individuals of likely Neanderthal identifi-

\footnotetext{
*Correspondence to:

Donovan M. Adams

Department of Anthropology

University of Nevada, Reno
}

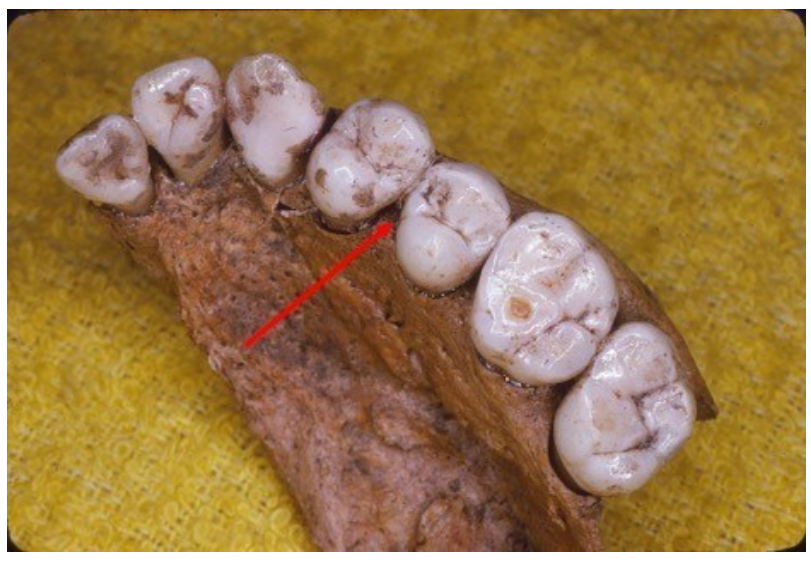

Figure 1. Mesial marginal accessory cusp on the left fourth premolar. Note the grooves separating the accessory cusp from the primary cusps.

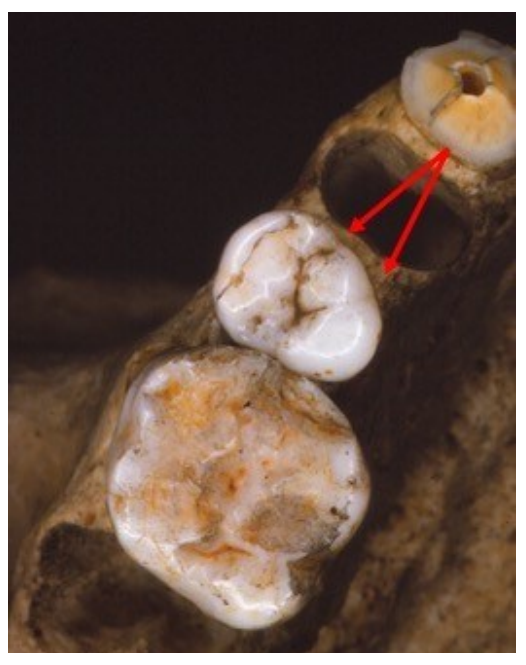

Figure 2. Mesial marginal accessory cusp present on right fourth premolar. Note the grooves separating the accessory cusp from the primary cusps. 
cation (Bailey, 2002; Bailey and Hublin, 2006; Glatz et al., 2008; Benazzi et al., 2011; Hershkovitz et al., 2016). Some argue that more complex occlusal morphology of the maxillary premolars, including accessory ridges and cusps, is characteristic of Neanderthals compared to anatomically modern humans (Benazzi et al., 2011). Bailey (2002) notes these cusps occur in a high frequency in Neanderthals, particularly on the third premolar, with the distal cusps occurring almost twice as often as mesial accessory cusps. In addition to Neanderthals, grade 3 expression of this trait was identified in hominin remains from Dmanisi, Georgia (Martinón-Torres et al., 2008).

Few studies have explicitly addressed the frequency of this trait in modern humans. A sample of AfroColombians from Guapi, who are of primarily African ancestry (with some contribution from Europeans and Native Americans), had high frequencies of marginal accessory cusps on both maxillary premolars (DelgadoBurbano, 2007). Marginal accessory cusps contributed to differentiating Asian from African and European populations in a study by Adams and George (2018) for forensic ancestry estimation. To compare Neanderthals to modern humans, small samples representing seven regions were examined by Bailey (2002). Frequencies of both distal and mesial accessory cusps were moderate to high for both premolars, with mesial cusps exhibiting higher rates of occurrence. No geographic pattern was evident regarding the highest frequencies for tooth or locus in this study; however, the largest sample size for any of these populations was 40 (Bailey, 2002). Global analyses of dental morphological variation conducted by Hanihara (2008) and Reyes-Centeno et al. (2017) suggest distinct differences between Asian populations and African and European populations, though this pattern differs for the third and fourth premolars. However, both studies used the ASUDAS grades, collapsing mesial and distal accessory cusps into a single presence grade, precluding a more nuanced observation.

This study provides a comprehensive analysis of the global distribution of the marginal accessory cusps of the maxillary premolars. A secondary objective is to evaluate the utility of distinguishing between locus of expression in population analyses.

\section{Materials and Methods}

Frequencies for marginal accessory cusps of the maxillary third (UP3) and fourth (UP4) premolars were calculated from the original data sheets of Christy G. Turner II on populations around the world (Table 1; see Scott et al., [2018] for more information on these subdivisions). While the original trait descriptions outlined by ASUDAS do not designate the placement of these cusps, the updated descriptions by Scott and Irish (2017) distinguish mesial, distal, and mesial + distal expressions. These categories are used to evaluate differences in geographic frequency distributions for each configuration. For those individuals with mesial + distal expressions (Grade 3), these were separated into mesial accessory cusp (MAC) expression (Grade 1) and distal accessory cusp (DAC) expression (Grade 2) for calculation.

Chi-square tests were used to identify differences between males and females for each tooth and locus. Sex was unknown for many individuals, so only individuals designated as male or female were used to test for sexual dimorphism. All statistical analyses were performed in $\mathrm{R}$ Studio 1.1.442.

\section{Results}

Marginal accessory cusps follow the general pattern of most dental morphological traits - little to no sex dimorphism. Total frequencies calculated for each population are presented in Tables $2 \mathrm{a}$ and $2 \mathrm{~b}$. Only the DAT of the fourth premolar in Polynesians exhibits statistically significant sexual dimorphism. Some populations produced a chi-square value of NA when the trait was absent for either males or females. A brief overview is provided for each tooth and locus.

UP3: MAC (Table 2a)

This trait occurs in low to moderate frequencies around the globe. Frequencies range between $0.0 \%$ and $35.4 \%$ for the pooled sex frequencies, with North Africa exhibiting

Table 1. Geographic regions analyzed in the present study.

\begin{tabular}{ll}
\hline Supra-Geographic Region & Geographic Subdivisions \\
\hline Western Eurasia & Eastern Europe, North Africa, Western Europe \\
Sub-Saharan Africa & West and South Africa \\
Sahul-Pacific & Australia, New Guinea, Melanesia \\
Sunda-Pacific & Southeast Asia (early), Southeast Asia (recent), Polynesia, Micronesia \\
Sino-Americas & East Asia, Northeast Siberia, American Arctic, Northwest Coast/Ne \\
& Dene, North America, Mesoamerica, South America, Jomon/Ainu \\
\hline
\end{tabular}


Table 2a. Frequencies for MAC and DAC for each population for the third premolar. $\chi 2$ values are present for degree of statistically significant differences between males and females. (fr $=$ frequency, $n=$ number of individuals, ${ }^{*}=$ statistically significant).

\begin{tabular}{|c|c|c|c|c|c|c|c|c|c|c|c|}
\hline \multirow[b]{2}{*}{ Population } & & \multicolumn{5}{|c|}{ MAC } & \multicolumn{5}{|c|}{ DAC } \\
\hline & & Male & Female & Total & $\chi^{2}$ & $\mathrm{p}$-value & Male & Female & Total & $\chi^{2}$ & $\mathrm{p}$-value \\
\hline \multirow{2}{*}{ West and South Africa } & $\mathrm{fr}$ & 0.000 & 0.111 & 0.023 & 0.523 & 0.470 & 0.176 & 0.000 & 0.140 & 0.669 & 0.414 \\
\hline & $\mathrm{n}$ & 34 & 9 & 43 & & & 34 & 9 & 43 & & \\
\hline \multirow{2}{*}{ Nubia } & $\mathrm{fr}$ & 0.125 & 0.000 & 0.077 & $<0.001$ & 1.000 & 0.125 & 0.200 & 0.154 & $<0.001$ & 1.000 \\
\hline & $\mathrm{n}$ & 8 & 5 & 13 & & & 8 & 5 & 13 & & \\
\hline \multirow{2}{*}{ North Africa } & $\mathrm{fr}$ & 0.000 & 0.000 & 0.000 & NA & NA & 0.000 & 0.000 & 0.000 & NA & NA \\
\hline & $\mathrm{n}$ & 12 & 3 & 15 & & & 12 & 3 & 15 & & \\
\hline \multirow{2}{*}{ South Asia } & $\mathrm{fr}$ & 0.025 & 0.000 & 0.019 & $<0.001$ & 1.000 & 0.000 & 0.071 & 0.019 & 0.307 & 0.579 \\
\hline & $\mathrm{n}$ & 40 & 14 & 54 & & & 40 & 14 & 54 & & \\
\hline \multirow{2}{*}{ Western Europe } & $\mathrm{fr}$ & 0.034 & 0.016 & 0.027 & 0.034 & 0.853 & 0.023 & 0.032 & 0.027 & $<0.001$ & 1.000 \\
\hline & $\mathrm{n}$ & 87 & 63 & 150 & & & 87 & 63 & 150 & & \\
\hline \multirow{2}{*}{ Eastern Europe } & fr & 0.023 & 0.066 & 0.040 & 1.601 & 0.206 & 0.015 & 0.022 & 0.018 & $<0.001$ & 1.000 \\
\hline & $\mathrm{n}$ & 132 & 91 & 223 & & & 132 & 91 & 223 & & \\
\hline \multirow{2}{*}{ Central Asia } & $\mathrm{fr}$ & 0.086 & 0.075 & 0.081 & 0.024 & 0.876 & 0.031 & 0.045 & 0.037 & 0.103 & 0.748 \\
\hline & $\mathrm{n}$ & 162 & 134 & 296 & & & 162 & 134 & 296 & & \\
\hline \multirow{2}{*}{ East Asia } & $\mathrm{fr}$ & 0.359 & 0.338 & 0.354 & 0.231 & 0.631 & 0.038 & 0.033 & 0.037 & 0.015 & 0.902 \\
\hline & $\mathrm{n}$ & 679 & 210 & 889 & & & 679 & 210 & 889 & & \\
\hline \multirow{2}{*}{ Northeast Siberia } & $\mathrm{fr}$ & 0.152 & 0.154 & 0.153 & $<0.001$ & 1.000 & 0.030 & 0.038 & 0.034 & $<0.001$ & 1.000 \\
\hline & $\mathrm{n}$ & 33 & 26 & 59 & & & 33 & 26 & 59 & & \\
\hline \multirow{2}{*}{ American Arctic } & $\mathrm{fr}$ & 0.174 & 0.144 & 0.159 & 0.341 & 0.560 & 0.007 & 0.006 & 0.006 & $<0.001$ & 1.000 \\
\hline & $\mathrm{n}$ & 149 & 160 & 309 & & & 149 & 160 & 309 & & \\
\hline \multirow{2}{*}{$\begin{array}{c}\text { Northwest Coast/Na } \\
\text { Dene }\end{array}$} & $\mathrm{fr}$ & 0.059 & 0.091 & 0.077 & $<0.001$ & 1.000 & 0.000 & 0.000 & 0.000 & NA & NA \\
\hline & $\mathrm{n}$ & 17 & 22 & 39 & & & 17 & 22 & 39 & & \\
\hline \multirow{2}{*}{ North America } & $\mathrm{fr}$ & 0.079 & 0.071 & 0.075 & $<0.001$ & 0.987 & 0.021 & 0.014 & 0.018 & $<0.001$ & 0.994 \\
\hline & $\mathrm{n}$ & 140 & 141 & 281 & & & 140 & 141 & 281 & & \\
\hline \multirow{2}{*}{ Mesoamerica } & fr & 0.041 & 0.025 & 0.034 & $<0.001$ & 1.000 & 0.000 & 0.025 & 0.011 & 0.010 & 0.919 \\
\hline & $\mathrm{n}$ & 49 & 40 & 89 & & & 49 & 40 & 89 & & \\
\hline \multirow{2}{*}{ South America } & $\mathrm{fr}$ & 0.075 & 0.067 & 0.071 & $<0.001$ & 0.987 & 0.037 & 0.044 & 0.041 & $<0.001$ & 1.000 \\
\hline & $\mathrm{n}$ & 134 & 135 & 269 & & & 134 & 135 & 269 & & \\
\hline \multirow{2}{*}{ Jomon/Ainu } & $\mathrm{fr}$ & 0.234 & 0.103 & 0.179 & 3.766 & 0.052 & 0.043 & 0.000 & 0.025 & 1.463 & 0.227 \\
\hline & $\mathrm{n}$ & 94 & 68 & 162 & & & 94 & 68 & 162 & & \\
\hline \multirow{2}{*}{ Southeast Asia (early) } & $\mathrm{fr}$ & 0.195 & 0.043 & 0.141 & 1.689 & 0.194 & 0.000 & 0.000 & 0.000 & NA & NA \\
\hline & $\mathrm{n}$ & 41 & 23 & 64 & & & 41 & 23 & 64 & & \\
\hline \multirow{2}{*}{ Southeast Asia (recent) } & $\mathrm{fr}$ & 0.146 & 0.145 & 0.145 & $<0.001$ & 1.000 & 0.046 & 0.048 & 0.047 & $<0.001$ & 1.000 \\
\hline & $\mathrm{n}$ & 323 & 124 & 447 & & & 323 & 124 & 447 & & \\
\hline Polvnesia & $\mathrm{fr}$ & 0.101 & 0.120 & 0.107 & 0.070 & 0.791 & 0.021 & 0.022 & 0.021 & $<0.001$ & 1.000 \\
\hline & $\mathrm{n}$ & 188 & 92 & 280 & & & 188 & 92 & 280 & & \\
\hline Micronesia & $\mathrm{fr}$ & 0.200 & 0.167 & 0.191 & 0.003 & 0.959 & 0.092 & 0.125 & 0.101 & 0.003 & 0.954 \\
\hline & $\mathrm{n}$ & 65 & 24 & 89 & & & 65 & 24 & 89 & & \\
\hline Melanesia & $\mathrm{fr}$ & 0.075 & 0.075 & 0.075 & $<0.001$ & 1.000 & 0.014 & 0.015 & 0.014 & $<0.001$ & 1.000 \\
\hline & $\mathrm{n}$ & 147 & 67 & 214 & & & 147 & 67 & 214 & & \\
\hline Australia & $\mathrm{fr}$ & 0.04 & 0.085 & 0.054 & 0.561 & 0.454 & 0.030 & 0.021 & 0.027 & 0.000 & 1.000 \\
\hline & $\mathrm{n}$ & 101 & 47 & 148 & & & 101 & 47 & 148 & & \\
\hline New Guinea & $\mathrm{fr}$ & 0.067 & 0.050 & 0.062 & $<0.001$ & 1.000 & 0.089 & 0.100 & 0.092 & $<0.001$ & 1.000 \\
\hline & $\mathrm{n}$ & 45 & 20 & 65 & & & 45 & 20 & 65 & & \\
\hline
\end{tabular}


Table 2b. Frequencies for MAC and DAC for each population for the fourth premolar. $\chi 2$ values are present for degree of statistically significant differences between males and females. (fr $=$ frequency, $n=$ number of individuals, ${ }^{*}=$ statistically significant).

\begin{tabular}{|c|c|c|c|c|c|c|c|c|c|c|c|}
\hline \multirow[b]{2}{*}{ Population } & & \multicolumn{5}{|c|}{ MAC } & \multicolumn{5}{|c|}{ DAC } \\
\hline & & Male & Female & Total & $\chi^{2}$ & $\mathrm{p}$-value & Male & Female & Total & $\chi^{2}$ & $\mathrm{p}$-value \\
\hline \multirow{2}{*}{$\begin{array}{c}\text { West and South } \\
\text { Africa }\end{array}$} & fr & 0.000 & 0.250 & 0.053 & 0.523 & 0.470 & 0.300 & 0.000 & 0.237 & 3.697 & 0.055 \\
\hline & $\mathrm{n}$ & 30 & 8 & 38 & & & 30 & 8 & 38 & & \\
\hline \multirow{2}{*}{ Nubia } & fr & 0.000 & 0.000 & 0.000 & NA & NA & 0.000 & 0.400 & 0.182 & 0.861 & 0.354 \\
\hline & $\mathrm{n}$ & 6 & 5 & 11 & & & 6 & 5 & 11 & & \\
\hline \multirow{2}{*}{ North Africa } & $\mathrm{fr}$ & 0.000 & 0.000 & 0.000 & NA & NA & 0.000 & 0.000 & 0.000 & NA & NA \\
\hline & $\mathrm{n}$ & 2 & 6 & 8 & & & 2 & 6 & 8 & & \\
\hline \multirow{2}{*}{ South Asia } & $\mathrm{fr}$ & 0.000 & 0.071 & 0.018 & 0.323 & 0.5696 & 0.024 & 0.000 & 0.018 & $<0.001$ & 1.000 \\
\hline & $\mathrm{n}$ & 41 & 14 & 55 & & & 41 & 14 & 55 & & \\
\hline \multirow{2}{*}{ Western Europe } & $\mathrm{fr}$ & 0.033 & 0.077 & 0.054 & 0.361 & 0.548 & 0.050 & 0.038 & 0.045 & $<0.001$ & 1.000 \\
\hline & $\mathrm{n}$ & 60 & 52 & 112 & & & 60 & 52 & 112 & & \\
\hline \multirow{2}{*}{ Eastern Europe } & fr & 0.033 & 0.037 & 0.035 & $<0.001$ & 1.000 & 0.056 & 0.085 & 0.070 & 0.218 & 0.641 \\
\hline & $\mathrm{n}$ & 90 & 82 & 172 & & & 90 & 82 & 172 & & \\
\hline \multirow{2}{*}{ Central Asia } & fr & 0.088 & 0.054 & 0.071 & 0.523 & 0.470 & 0.053 & 0.054 & 0.053 & $<0.001$ & 1.000 \\
\hline & $\mathrm{n}$ & 114 & 111 & 225 & & & 114 & 111 & 225 & & \\
\hline \multirow{2}{*}{ East Asia } & fr & 0.102 & 0.059 & 0.091 & 2.996 & 0.083 & 0.034 & 0.039 & 0.035 & 0.017 & 0.897 \\
\hline & $\mathrm{n}$ & 649 & 205 & 854 & & & 649 & 205 & 854 & & \\
\hline \multirow{2}{*}{ Northeast Siberia } & $\mathrm{fr}$ & 0.036 & 0.053 & 0.043 & $<0.001$ & 1.000 & 0.000 & 0.000 & 0.000 & NA & NA \\
\hline & $\mathrm{n}$ & 28 & 19 & 47 & & & 28 & 19 & 47 & & \\
\hline \multirow{2}{*}{ American Arctic } & $\mathrm{fr}$ & 0.022 & 0.026 & 0.024 & $<0.001$ & 1.000 & 0.011 & 0.026 & 0.020 & 0.110 & 0.740 \\
\hline & $\mathrm{n}$ & 92 & 156 & 248 & & & 92 & 156 & 248 & & \\
\hline \multirow{2}{*}{$\begin{array}{l}\text { Northwest Coast/ } \\
\text { Na Dene }\end{array}$} & $\mathrm{fr}$ & 0.000 & 0.000 & 0.000 & NA & NA & 0.000 & 0.000 & 0.000 & NA & NA \\
\hline & $\mathrm{n}$ & 12 & 19 & 31 & & & 12 & 19 & 31 & & \\
\hline \multirow{2}{*}{ North America } & $\mathrm{fr}$ & 0.033 & 0.034 & 0.033 & $<0.001$ & 1.000 & 0.044 & 0.034 & 0.038 & $<0.001$ & 1.000 \\
\hline & $\mathrm{n}$ & 91 & 118 & 209 & & & 91 & 118 & 209 & & \\
\hline \multirow{2}{*}{ Mesoamerica } & fr & 0.030 & 0.000 & 0.015 & $<0.001$ & 1.000 & 0.061 & 0.030 & 0.045 & $<0.001$ & 1.000 \\
\hline & $\mathrm{n}$ & 33 & 33 & 66 & & & 33 & 33 & 66 & & \\
\hline \multirow{2}{*}{ South America } & fr & 0.053 & 0.027 & 0.037 & 0.296 & 0.586 & 0.027 & 0.045 & 0.037 & 0.058 & 0.809 \\
\hline & $\mathrm{n}$ & 75 & 112 & 187 & & & 75 & 112 & 187 & & \\
\hline \multirow{2}{*}{ Jomon/Ainu } & fr & 0.089 & 0.063 & 0.077 & 0.071 & 0.790 & 0.000 & 0.031 & 0.014 & 0.750 & 0.386 \\
\hline & $\mathrm{n}$ & 79 & 64 & 143 & & & 79 & 64 & 143 & & \\
\hline \multirow{2}{*}{$\begin{array}{l}\text { Southeast Asia } \\
\text { (early) }\end{array}$} & fr & 0.074 & 0.083 & 0.078 & $<0.001$ & 1.000 & 0.074 & 0.000 & 0.039 & 0.407 & 0.524 \\
\hline & $\mathrm{n}$ & 27 & 24 & 51 & & & 27 & 24 & 51 & & \\
\hline \multirow{2}{*}{$\begin{array}{l}\text { Southeast Asia } \\
\text { (recent) }\end{array}$} & $\mathrm{fr}$ & 0.062 & 0.071 & 0.064 & 0.012 & 0.912 & 0.079 & 0.106 & 0.086 & 0.468 & 0.494 \\
\hline & $\mathrm{n}$ & 292 & 113 & 405 & & & 292 & 113 & 405 & & \\
\hline Polynesia & fr & 0.056 & 0.082 & 0.066 & 0.345 & 0.557 & 0.043 & 0.134 & 0.077 & 5.805 & $0.016^{*}$ \\
\hline & $\mathrm{n}$ & 162 & 97 & 259 & & & 162 & 97 & 259 & & \\
\hline Micronesia & fr & 0.190 & 0.167 & 0.184 & $<0.001$ & 1.000 & 0.159 & 0.167 & 0.161 & $<0.001$ & 1.000 \\
\hline & $\mathrm{n}$ & 63 & 24 & 87 & & & 63 & 24 & 87 & & \\
\hline Melanesia & fr & 0.075 & 0.102 & 0.083 & 0.119 & 0.730 & 0.067 & 0.102 & 0.078 & 0.285 & 0.594 \\
\hline & $\mathrm{n}$ & 134 & 59 & 193 & & & 134 & 59 & 193 & & \\
\hline Australia & fr & 0.167 & 0.120 & 0.151 & 0.254 & 0.614 & 0.083 & 0.06 & 0.075 & 0.031 & 0.860 \\
\hline & $\mathrm{n}$ & 96 & 50 & 146 & & & 96 & 50 & 146 & & \\
\hline New & fr & 0.182 & 0.125 & 0.162 & 0.069 & 0.792 & 0.182 & 0.083 & 0.147 & 0.544 & 0.461 \\
\hline & $\mathrm{n}$ & 44 & 24 & 68 & & & 44 & 24 & 68 & & \\
\hline
\end{tabular}


the lowest and East Asians the highest prevalence of the trait. A distinct pattern is evident regarding Asian and Asian-derived populations. East Asians have the highest frequency of this trait (35.4\%). Northeastern Siberians (15.3\%), American Arctic (15.9\%), Jomon/ Ainu (17.9\%), Southeast Asia (early: 14.1\%; recent: $14.5 \%$ ), and Micronesia (19.1\%) have intermediate frequencies. Native American [Northwest Coast/Na Dene $(7.7 \%)$, North America (7.5\%), Mesoamerica (3.4\%), South America (7.1\%)] and Pacific (Polynesia [10.7\%], Melanesia [7.5\%]) groups exhibit the lowest frequencies for Asian-derived groups. In general, from the point of highest prevalence in East Asia, frequencies decrease into the Americas and the Pacific.

The lowest frequencies of MAC on UP3 are found in Western Eurasian $(0.0 \%-4.0 \%)$, African $(2.3-7.7 \%)$, and Sahul-Pacific groups $(5.4 \%-6.2 \%)$.

\section{UP3: DAC (Table 2a)}

The distal accessory cusps exhibit a different pattern of geographic variation than the mesial variant on UP3. This trait typically occurs in low frequencies, ranging from $0.0 \%$ to $15.4 \%$. Sub-Saharan Africans and some Pacific Island groups display the highest rates. West/ South Africa and Nubia have the highest frequencies with $14.0 \%$ and $15.4 \%$, respectively. Although sample sizes are small for this region, this finding may indicate higher frequencies of UP3 DAC are characteristic of Sub-Saharan populations. New Guinea (9.2\%) and Micronesia (10.1\%) exhibit similar frequencies for the third premolar. Other global populations typically have a presence rate of less than $4.0 \%$. North American groups range from $0.0 \%$ to $1.8 \%$, while South American groups have a frequency of $4.1 \%$, comparable to Central and East Asia. Melanesian (1.4\%), Polynesian $(2.1 \%)$, and Australian $(2.7 \%)$ groups exhibit similar frequencies for DAC on the third premolar. Western Eurasian populations (ranging from 0.0 to $2.7 \%$ ) are comparable to samples from the Americas.

\section{UP4: MAC (Table 2b)}

Cusp frequencies on this tooth are significantly lower than on the third premolar, with the highest incidence at $18.4 \%$ for Micronesians. Australians and New Guineans have slightly lower frequencies with rates of $15.1 \%$ and $16.2 \%$, respectively. Melanesians, Polynesians, and Southeast Asians have comparable rates at $8.3 \%, 6.6 \%$, and $6.4 \%$ (recent) $/ 7.8 \%$ (early), respectively. These rates are intermediate to Sahul-Pacific and East Asian (9.1\%) frequencies. The trait is uncommon in the Americas, with frequencies ranging from $0.0 \%$ (Northwest Coast/Ne Dene) to 3.7\% (South America).

Western European MAC frequencies increase from $2.7 \%$ on UP3 to $5.4 \%$ on UP4. However, Eastern Euro- peans decrease from $4.0 \%$ to $3.5 \%$. Less variation is present between populations due to uniformly low frequencies; however, there is some clustering of populations who most commonly exhibit this trait.

\section{UP4: DAC (Table 2b)}

While this trait typically occurs in low frequencies, African populations (West and South Africa: $23.7 \%$, Nubia: $18.2 \%)$, along with Micronesia (16.1\%), and New Guinea (14.7\%), are exceptions to this trend. Melanesian $(7.8 \%)$, Polynesian (7.7\%), and Australian (7.5\%) groups exhibit similar frequencies for the fourth premolar DAC. New Guinea (14.7\%) and Micronesia (16.1\%) exhibit slightly higher frequencies. North American (3.8\%), Mesoamerican (4.5\%), and South American $(4.5 \%)$ groups have a higher presence of DAT than northern indigenous groups (American Arctic: $2.0 \%$, Northwest Coast/Na Dene: $0.0 \%$ ).

European DAC frequencies increase significantly on UP4 compared to UP3, increasing from to $2.7 \%$ to $4.5 \%$ in Western Europeans and 1.8\% to 7.0\% in Eastern Europeans. General regional differences are relatively similar between DAC of UP3 and DAC of UP4.

\section{Discussion}

Marginal accessory cusps of UP3 follow a pattern that corresponds to known population histories. Most notable is the distribution of this trait among Asian-derived populations. East Asian groups exhibit the highest frequencies $(35.4 \%)$. This trait decreases in occurrence in more northern and southern Asian populations and in the Americas. Turner (1971) found a distinction between American Arctic and Native American groups in the rest of North America, with the former having three -rooted lower first molar frequencies of approximately $27-47 \%$ and the latter having a frequency of about $6 \%$. The prevalence of the three-rooted LM1 was used to argue for a three-wave model of migration into the Americas: 1) the first being Amerinds [North and South American Indians], 2) the second being Northwest Coast groups and Na Dene speakers, 3) and the third being the ancestors of American Arctic groups (Turner 1971). Here there is a distinction between American Arctic populations (15.9\%) and North and South American Indian groups ranging between 3.4 and $7.7 \%$. The intermediacy of Northwest Coast/Na Dene populations found in previous dental morphological and genetic studies (Turner 1985; Powell 1993; Cavalli-Sforza et al. 1994; Scott and Turner 2008) is not present in this study. For marginal premolar cusps, this population has frequencies like Native North and South American groups.

The variation of MAC on UP3 also corresponds to the Sinodont-Sundadont dental complexes defined by 
Turner (1981). The Sinodont complex is characterized by the addition of enamel and increased crown complexity, in contrast to the more simplified dental pattern that distinguishes the Sundadont complex (Turner 1981, 1985). This pattern does not extend to the fourth premolar or to the presence of UP3 DAC; however, the variation of this trait and its patterned distribution that follows known population history indicates MAC of UP3 is informative for studies of population affinity.

Additionally, the mesial accessory cusp reflects the expected intermediacy of Central Asian populations compared to East Asia and Western Eurasia. This region is intermediate in trait expression for shoveling, enamel extensions, cusp 6, protostylid, three-rooted LM1, and four-cusped LM2 (Heim et al., 2016). It has been postulated that this position between these two distinct complexes is a result of gene flow associated with the complex migration histories in the central region of Eurasia (Heim et al., 2016), rather than a settlement zone for early modern humans when first moving out of Africa before expanding into Europe and East Asia (MartínezCruz et al., 2011). This same pattern is not evident for the distal accessory cusp. Central Asians exhibit higher frequencies of this trait for the third and fourth premolars than both Western Eurasians and East Asians.

The lowest frequencies for DAC and MAC are found in Western Eurasian populations, particularly in North Africa and South Asia. North Africa is the only group to lack either of these traits on any tooth, though sample size is small. South Asia, represented by India, does not exceed $2.0 \%$ for either trait on UP3 or UP4. European populations typically exhibit low frequencies of these traits. This corresponds to the general pattern of simplification of the dental crowns in these populations (Scott et al., 2018).

The MAC frequencies indicate a close relationship between Southeast Asia, Polynesia, and Micronesia for the third premolar, but between Southeast Asia, Polynesia, and Melanesia for the fourth premolar. Additionally, for DAC, the closest similarities are between Southeast Asia, Melanesia, Polynesia, and Australia and between New Guinea and Micronesia for both premolars. While these are univariate comparisons, it is evident that if taken together, these populations exhibit slight clinal variation from their place of origin in Southeast Asia. A mean measure of divergence global analysis of 21 crown traits and six root traits also found a greater similarity between Polynesians and Melanesians than between Polynesians and Micronesians (Scott et al., 2018). The differences between trait and tooth may be reflective of different underlying genetic inheritance patterns and complex migration histories. For instance, while Melanesia is typically associated with Sahul-Pacific groups (Scott et al. 2018), Melanesia is the origin of the Lapita culture that spread into Polynesia. It is hypothesized that it is from the area surrounding the Santa Cruz Islands, Reef Islands, and Vanuatu (i.e., "Central Island Melanesia") where they migrated in multiple waves to remote Oceania, producing an indistinct biological, cultural, and linguistic boundary (Wollstein, 2010; Burley, 2013; Skoglund et al., 2016).

Previous studies of New Guinea dentition revealed an unexpected similarity to the European dental complex (Scott and Turner, 1997; Scott and Schomberg, 2016). Marginal accessory cusps, however, conform to the pattern of expected biological relationships. Mesial accessory cusps occur in frequencies most like Australians for both the third (A: $5.4 \%$, NG: $6.2 \%$ ) and fourth (A: $15.1 \%$, NG: $16.2 \%$ ) premolars. The distal accessory cusps for New Guinea are, however, most like Micronesian populations for both the third (Mic: 10.1\%, NG: 9.2\%) and fourth (Mic: 16.1\%, NG: 14.7\%) premolars.

Distal accessory cusps exhibit an interesting pattern where their highest prevalence is in the Pacific and Sub-Saharan Africa. African samples are rather small compared to the Pacific groups included here, so further data collection is required to substantiate this finding. Hanihara (2008) found low frequencies for premolar accessory cusps in a larger sample size of Sub-Saharan Africans; however, different samples and method of analysis (the author combined mesial and distal in a dichotomous presence/absence scale) preclude comparison. In general, the results of the present study are like those of Hanihara (2008), with East Asians exhibiting the highest frequencies of accessory cusps on the third premolar while Micronesian and Sahul-Pacific populations have the highest frequencies on the fourth premolar.

The differences found in the distribution of MAC and DAC in the same global populations suggest these traits should be separated for biological distance analyses. Although DAC occurs in lower frequencies than MAC, and most populations exhibit uniformly low frequencies, the patterns present suggest genetic drift affected the distribution of this trait. The distribution of MAC and its correspondence to known population histories of Sinodont and Sundadont populations indicate this trait may be included as part of the suite of traits characterizing these dental complexes and may be informative in understanding the migration of populations out of East and Southeast Asia. 
Previous research has indicated varied rates of intra- and interobserver reliability when scoring this trait. Various studies have exhibited low replicability between observers and by a single observer (Nichol and Turner, 1986; Griffin, 1989; Powell, 1995; Aubry, 2009; Stojanowski and Johnson, 2015; Marado et al., 2017). This is likely due, in part, to the absence of a dentine component of these cusps, which results in the obliteration of the trait given a minimal level of wear (Turner et al., 1991; Scott and Irish, 2017). Other researchers have found significant levels of intra-observer replicability (Hubbard, 2012, Thompson, 2013; Passalacqua, 2015; Maier, 2017). As all individuals included in this analysis were investigated by a single observer (C.G.T. II) using the scoring system in ASUDAS, inter-observer error is not a concern in this study. Turner and colleagues (1991) recommend this trait should not be scored on teeth with significant wear, generally limiting analyses to younger individuals. It is important to remember when scoring accessory cusps that grooves must distinctly separate them from the primary buccal and lingual cusps. If wear precludes the ability to observe these grooves, it is best to not grade the trait.

\section{Conclusions}

This study is the first to outline the world variation of mesial and distal accessory cusps on the upper third and fourth premolars. It lays a foundation for better understanding the geographic patterning of this underutilized trait. To a large extent, the variation of these cusps reflects known population histories, particularly regarding the mesial accessory cusp of the upper third premolar. Distinctive trends are evident in the distribution of each trait on UP3 and UP4, indicating their utility in studies of biological relationships. The different geographic patterns between mesial and distal accessory cusps are difficult to explain but may suggest the traits experienced different evolutionary histories. As a result, these traits should be treated separately in biodistance statistics rather than collapsed into a scale that tallies mesial and distal cusps together.

\section{Acknowledgments}

The authors acknowledge the extraordinary efforts of the late Christy G. Turner II who collected dental morphological data on 23,000 individuals around the world. Although no longer with us, his legacy lives on.

\section{REFERENCES}

Adams, D. M., \& George R. L. (2018). Fuzzy inference systems (FIS) as a novel approach to forensic ancestry estimation. Proceedings of the American Academy of Forensic Sciences. Seattle, Washing- ton.

Aubry, B. S. (2009). Population Structure and Interregional Interaction in Pre-Hispanic Mesoamerica: A Biodistance Study. [Ph.D. Dissertation.] Columbus, $\mathrm{OH}$ : The Ohio State University.

Bailey, S. E. (2002). Neanderthal Dental Morphology: Implications for Modern Human Origins. (Doctoral dissertation). Tempe, AZ: Arizona State University.

Bailey, S. E., \& Hublin, J.-J. (2006). Dental remains from the Grotte du Renne at Arcy-sur-Cure (Yonne). Journal of Human Evolution, 50, 485-508.

Benazzi, S., Viola, B., Kullmer, O., Fiorenza, L., Harvati, K., Paul, T., Gruppioni, G., Weber, G. W., \& Mallegni, F. (2011). A reassessment of the Neanderthal teeth from Taddeo cave (southern Italy). Journal of Human Evolution, 61, 377-387.

Burley, D. V. (2013). Fijian polygenesis and the Melanesian/Polynesian divide. Current Anthropology, $54,436-462$.

Cavalli-Sforza, L. L., Menozzi, P., \& Piazza, A. (1994). The History and Geography of Human Genes. Princeton: Princeton University Press.

Delgado-Burbano, M. A. (2007). Population affinities of African Colombians to Sub-Saharan Africans based on dental morphology. HOMO - Journal of Comparative Human Biology, 58, 329-356.

Glantz, M., Viola, B., Wrinn, P., Chikisheva, T., Derevianko, A., Krivoshapkin, A., Islamov, U., Suleimanov, R., \& Titzman, T. (2008). New hominin remains from Uzbekistan. Journal of Human Evolution, 55, 223-237.

Griffin, M C. (1989). Dental Variation of Native Populations from Northern Spanish Florida. [Master's thesis]. Dekalb, IL: Northern Illinois University.

Hanihara, T. (2008). Morphological variation of major human populations based on nonmetric dental traits. American Journal of Physical Anthropology, 136, 169-182.

Heim, K., Maier, C., Pilloud, M. A., Scott, G. R. (2016). Crossroads of the Old World: Dental morphological data and the evidence for a Eurasian cline. In: M. A. Pilloud \& J. T. Hefner (Eds.), Biological Distance Analysis: Forensic and Bioarchaeological Perspectives. (pp. 391-410). Amsterdam: Academic Press.

Hershkovitz, I., Weber, G. W., Fornai, C., Gopher, A., Barkai, R., Slon, V., Quam, R., Gabet, Y., \& Sarig, R. (2016). New Middle Pleistocene dental remains from Qesem Cave (Israel). Quaternary International, 398, 148-158.

Hubbard, A. R. (2012). An Examination of Population History, Population Structure, and Biological Distance Among Regional Populations of the Kenyan Coast using Genetic and Dental Data. [Ph.D. Dissertation]. Columbus, $\mathrm{OH}$ : The Ohio State University. 
Maier, C. A. (2017). The Combination of Cranial Morphoscophic and Dental Morphological Methods to Improve the Forensic Estimation of Ancestry. [Ph.D. Dissertation]. Reno, NV: University of Nevada, Reno.

Martínez-Cruz, B., Vitalis, R., Ségurel, L., Austerlitz, F., Georges, M., Théry, S., Quintana-Murci, L., Hegay, T., Aldashev, A., Nasyrova, F., \& Heyer, E. (2011). In the heartland of Eurasia: The multilocus genetic landscape of Central Asian populations. European Journal of Human Genetics, 19, 216223.

Martinón-Torres, M., Bermúdez de Castro, J. M., Gómez-Robles, A., Margvelashvili, A, Prado, L, Lordkipanidze, D., \& Vekua, A. (2008). Dental remains from Dmanisi (Republic of Georgia): Morphological analysis and comparative study. Journal of Human Evolution, 55, 249-273.

Morado, L. M., Silva, A. M., \& Irish, J. D. (2017). Fluctuating asymmetry in dental and mandibular nonmetric traits as evidence for childcare sex bias in $19^{\text {th }} / 20^{\text {th }}$ century Portugal. HOMO - Journal of Comparative Human Biology, 68, 18-29.

Nichol, C. R., \& Turner, II, C. G. (1986). Intra- and interobserver concordance in classifying dental morphology. American Journal of Physical Anthropology, 69, 299-315.

Passalacqua, K. Z. (2015). An Investigation of Late Woodland and Mississippian Biological Relationships Using Odontometric and Dental Non-metric Trait Analyses. [Ph.D. Dissertation]. Bloomington, IN: Indiana University.

Powell, J. F. (1993). Dental evidence for the peopling of the New World: Some methodological considerations. Human Biology, 65, 799-815.

Powell, J. F. (1995). Dental Variation and Biological Affinity Among Middle Holocene Human Populations in North America. [Ph.D. Dissertation]. College Station, TX: Texas A\&M University.

Reyes-Centeno, H., Rathmann, H., Hanihara, T., Harvati, K. (2017). Testing modern human Outof-Africa dispersal models using dental nonmetric data. Current Anthropology, 58, S406-S417.

Skoglund, P., Posth, C., Sirak, K., Spriggs, M., Valentin, F., Bedford, S., Clark, G. R., Reepmeyer, C., Petchey, F., Fernandes, D., Fu, Q., Harney, E., Lipson, M., Mallick, S., Novak, M., Rohland, N., Stewardson, K., Abdullah, S., Cox, M. P., Friedlaender, F. R., Friedlaender, J. S., Kivisild, T., Koki, G., Kusuma, P., Merriwether, D. A., Ricaut, F-X., Wee, J. T. S., Patterson, N., Krause, J., Pinhasi, R., \& Reich, D. (2016). Genomic insights into the peopling of the Southwest Pacific. $\mathrm{Na}$ ture, 538, 510-513.

Scott, G. R., \& Irish J. D. (2017). Tooth Crown and Root Morphology: The Arizona State University Dental
Anthropology System. Cambridge: Cambridge University Press.

Scott, G. R., \& Schomberg, R. (2016). A baffling convergence: Tooth crown and root traits in Europe and New Guinea. In: M. A. Pilloud \& J. T. Hefner (Eds.), Biological Distance Analysis: Forensic and Bioarchaeological Perspectives. (pp. 411-424). Amsterdam: Academic Press.

Scott, G. R., \& Turner, C. G., II. (1997). The Anthropology of Modern Human Teeth: Dental Morphology and Its Variation in Recent Human Populations. Cambridge: Cambridge University Press.

Scott, G. R., \& Turner, C. G., II. (2008). The physical anthropological intermediacy problem of NaDené/Greater Northwest Coast Indians. Alaska Journal of Anthropology, 6, 57-68.

Scott, G. R., Turner, C. G., Townsend, G. C., \& Martinón-Torres M. (2018). The Anthropology of Modern Human Teeth: Dental Morphology and Its Variation in Recent and Fossil Homo sapiens. Cambridge: Cambridge University Press.

Stojanowski, C. M., \& Johnson, K. M. (2015). Observer error, dental wear, and the inference of New World sundadonty. American Journal of Physical Anthropology, 156, 349-362.

Thompson, A. R. (2013). An Analysis of Biological Variation During the Late Woodland-Mississippian Period in the Midwest Using the Dentition. [Ph.D. Dissertation] Bloomington, IN: Indiana University.

Turner, C. G. (1971). Three-rooted mandibular first permanent molars and the question of American Indian origins. American Journal of Physical Anthropology, 34, 229-241.

Turner, C. G. (1985). Dental evidence for the peopling of the Americas. National Geographic Society Research Reports, 19, 573-596.

Turner, C. G. (1987). Late Pleistocene and Holocene population history of East Asia based on dental variation. American Journal of Physical Anthropolo$g y, 73,305-321$.

Turner, C. G., Nichol, C. R., \& Scott, G. R. (1991). Scoring procedures for key morphological traits of the permanent dentition: The Arizona State University dental anthropology system. In M. A. Kelley \& C. S. Larsen. (Eds.), Advances in Dental Anthropology. (pp. 13-31). New York: Wiley-Liss.

Wollstein, A., Lao, O., Becker, C., Brauer, S., Trent, R. J., Nürnberg, P., Stoneking, M., \& Kayser, M. (2010). Demographic history of Oceania inferred from genome-wide data. Current Biology, 20, 1983-1992. 